\title{
Nanoparticles of $\operatorname{In}_{2} \mathrm{O}_{3} / \mathrm{SnO}_{2}(90 / 10)$ and (80/20) at Two Different Proportions and Its Properties
}

\author{
Abbas Ayeshamariam ${ }^{1 *}$, Vinodh Sundar Vidhya ${ }^{2}$, Thangavel Sivakumar ${ }^{3}$, Ramasamy Mahendran ${ }^{4}$, \\ Ramasamy Perumalsamy ${ }^{5}$, Nallasamy Sethupathy ${ }^{6}$, Muthurulandi Jayachandran ${ }^{7}$ \\ ${ }^{1}$ Department of Physics, Khadir Mohideen College, Adirampattinam, India \\ ${ }^{2}$ Department of Chemistry, Chendhuran College of Engineering and Technology, Pudukottai, India \\ ${ }^{3}$ Department of Electronics, RVS College of Arts and Science, Sulur, Coimbatore, India \\ ${ }^{4}$ Department of Electronics, Government Arts College, Kulithalai, India \\ ${ }^{5}$ Department of Physics, Sir Theagaraya College Higher Secondary School, Chennai, India \\ ${ }^{6}$ Department of Physics, Arignar Anna Government Arts College, Namakkal, India \\ ${ }^{7}$ Electro Chemical Material Science Division, (CSIR) Central Electro Chemical Research Institute, Karaikudi, India \\ Email: "ashammakmc@yahoo.com, appachi786@yahoo.com
}

Received March 25, 2013; revised April 25, 2013; accepted May 3, 2013

Copyright (C) 2013 Abbas Ayeshamariam et al. This is an open access article distributed under the Creative Commons Attribution License, which permits unrestricted use, distribution, and reproduction in any medium, provided the original work is properly cited.

\begin{abstract}
ITO nanoparticles were obtained by combustion reaction of urea as fuel. The gel form structures were fired at $350^{\circ} \mathrm{C}$ in furnace for $20 \mathrm{~min}$ to yield powdery products and these products were calcined to five different temperatures from $100^{\circ} \mathrm{C}$ to $500^{\circ} \mathrm{C}$ for an hour to yield ITO powders. From the scanning electron microscopy (SEM) photographs and particle size analysis the average sizes of the cubic particle of powders are found to be less than $15 \mathrm{~nm}$ and less than $20 \mathrm{~nm}$ respectively. The ratio of doping concentration In/Sn is 90/10 and 80/20. The X-ray diffraction (XRD) data were evaluated by Scherer equation for the estimation of the average crystal size of the powders (less than $20 \mathrm{~nm}$ ) for $90 / 10$ and (less than $25 \mathrm{~nm}$ ) for 80/20. The synthesized ITO powder characterized by XRD, UV-Vis-NIR and PL shows high specific surface area and possesses small primary crystallite size and good optical band gap.
\end{abstract}

Keywords: XRD; UV-Vis-NIR; Photoluminescence and SEM

\section{Introduction}

Tin-doped indium oxide (ITO) nanoparticles and nano thin films are being extensively prepared because of the useful properties they could have, such as a low resistivity, transparency in the visible region of the electromagnetic spectrum and high infrared reflectivity. ITO has a cubic structure, characteristics of semiconductors, and is used in automobile measuring instruments, surface acoustic devices, optoelectronic devices and solar cells [1]. Nanoscale particles possess different physical and chemical properties compared to bulk materials. Nowadays, many methods are generally being used to obtain nanosized oxide powders, and combustion method is one of them. ITO is recently used for various optical coatings, most notably infrared-reflecting coatings for automotive, and sodium vapor lamp glasses. Also its uses include gas sensors, antireflection coatings and electro-wetting on dielectrics.

\footnotetext{
"Corresponding author.
}

S. Deki et al. reported the liquid-phase methods include liquid phase precipitation, hydrothermal (high temperature hydrolysis), Sol-gel (colloidal chemistry), radiation chemical synthesis, and so forth [2]. A. Nakata et al. reported about the ITO nanoparticles, which will be used in spray coating of ITO thin film, are prepared by liquid-phase co-precipitation with indiumchloride and tin chloride as main raw material [3]. A. Soliman et al. reported that ITO films prepared by sol-gel technique present are latively high resistance. The reasons for the lowconductivity of sol-gel processed ITO films may result from their considerable porosity even after sintering at a high temperature [4]. The aim of this study was to see the effect of the heat treatment conditions in air atmospheres and the structural, optical properties of ITO particles.

\section{Experimental}

The starting materials for $\mathbf{I n}_{2} \mathbf{O}_{3}-\mathbf{S n O}_{2}$ powder were prepared with indium in $\left(\mathrm{NO}_{3}\right)_{2} \cdot 3 \mathrm{H}_{2} \mathrm{O}$, ingots $(>99.9 \%$, Sisco research laboratory) and $\mathbf{S n}\left(\mathrm{NO}_{3}\right)_{2} \cdot 2 \mathrm{H}_{2} \mathrm{O}(98 \%$ Lo- 
baChemie). A stock solution of indium in

$\left(\mathrm{NO}_{3}\right)_{2} \cdot 2 \mathrm{H}_{2} \mathrm{O}$, ingots $(>99.9 \%$, Sisco research laboratory) and $\mathbf{S n}\left(\mathbf{N O}_{3}\right)_{2} \cdot \mathbf{3} \mathbf{H}_{2} \mathbf{O}(98 \%$ LobaChemie) was prepared by dissolving shredded indium and tin ingots in concentrated nitric acid (35.4\% AR, sd fine chem.) so as to obtain a concentration of $0.48 \mathrm{M} \mathbf{I n}^{3+}$. For the preparation of $90: 10$ and $80 / 20 \mathrm{In} / \mathrm{Sn}$ oxide powders, a calculated quantity of In $\left(\mathbf{N O}_{3}\right)_{2} \cdot \mathbf{2} \mathbf{H}_{2} \mathrm{O}$ and $\mathrm{Sn}\left(\mathrm{NO}_{3}\right)_{2} \cdot \mathbf{3} \mathbf{H}_{2} \mathrm{O}$ was dissolved in the required amount of water. The resulting mixed solution was added to $\left(\mathbf{C O}\left(\mathbf{N H}_{2}\right)_{2}\right)(A R$, sd fine chem.). The volume ratio of the mixed salt solution/organic solvent was 9:1 and 8:2. This precursor was aged under a room temperature for 24 hrs. Precipitation as a mixed hydrous oxide was effected at a $\mathrm{pH}$ of $8-9$ with the addition of urea as reducing agent. The solution was heated under constant stirring at a temperature of about $100^{\circ} \mathrm{C}$ in a Pyrex vessel on a hot plate. Then the concentration of the solution slowly became higher. Eventually a gel form precursors are formed, when the temperature of the hot plate was raised to about $100^{\circ} \mathrm{C}$, the precursor underwent a strong self sustaining combustion reaction with evolution of gases in a large volume and swelled into voluminous and foamy ashes. The resulting ashes were then fired at a temperature higher than $350^{\circ} \mathrm{C}$ until complete decomposition of the residues was achieved. The above procedure was repeated for $80 / 20$ ratio of different experimental conditions. The dried powders were calcined at various temperatures $100^{\circ} \mathrm{C}$, $200^{\circ} \mathrm{C}, 300^{\circ} \mathrm{C}, 400^{\circ} \mathrm{C}$ and $500^{\circ} \mathrm{C}$ for $1 \mathrm{~h}$ to examine the crystallization behaviour.

\subsection{Mode of Synthesis}

The Combustion method is a useful technique that has been shown to be good preparation route for ITO nanopowders. It is based on exothermic and usually very rapid chemical reaction between metal nitrates as an oxidizer and an organic fuel, such as Urea, glycine and so on. A key feature of the method is that heat is required to maintain the chemical reaction supplied from the reaction itself that is not from an external source but from an internal one. Therefore to achieve an optimized combustion reaction condition, many chemical reaction parameters must be considered. Among these, the main parameters which influence the reaction include, type of fuel to oxidizer ratio, uses of excess oxidizer ignition temperature, and water content of the precursor mixture, [5] among known fuels we used the urea which had the versatility of Combustion synthesis methods by showing successful preparation of a large number of well crystallized multicomponent oxides. In this study, the amount of urea was fixed at $24 \mathrm{~g} / \mathrm{mol}$. The ratio 90:10, 80:20 was taken in a Pyrex vessel and this ratio was mixed with pure water. The solution was heated under constant stir- ring at a temperature of about $100^{\circ} \mathrm{C}$ in a Pyrex vessel on a hot plate. Then the concentration of the solution slowly became higher. Now the vessel was placed in a furnace and the temperature was raised to about $350^{\circ} \mathrm{C}$, the precursor underwent a strong, self sustaining Combustion reaction with evolution of gases in a large volume and swelled into voluminous and foamy ashes. The entire combustion process ended in a few seconds. The resulting ashes were then fired at a temperature higher than $350^{\circ} \mathrm{C}$ until complete decomposition of the residues was achieved. Stoichiometric amounts of the starting material were thoroughly stirred.

According to cooper et al., we can define the oxygen Balance $\mathrm{OB}$ of the reaction

$$
(\mathrm{OB}) \%=100 \times \frac{\mathrm{AW}_{\text {oxygen }}}{\mathrm{FW}_{\text {mixture }}} \times 2 \gamma \mathrm{O}_{2}
$$

$\mathrm{AW}=$ Atomic weight of oxygen

$\mathrm{FW}=$ Formula weight of the mixture

$\gamma \mathrm{O}_{2}=$ Molar number of oxygen

The modes of combustion for preparing ITO in this present study is fuel-lean regime smoldering Combustion Synthesis (SCS) taken place, an excess amount o oxygen in the reactant mixture is present and stifled the reaction. This mode is characterized by slow and flameless reaction. SCS used all over the world to prepare oxide materials for a variety of application. An oxide material prepared by rapidly heating aqueous solutions containing stoichiometric amounts of respective metal nitrate (oxidize) and fuels like urea. Source of carbon (C) and hydrogen $(\mathrm{H})$ on combustion form $\mathrm{CO}_{2}$ and $\mathrm{H}_{2} \mathrm{O}$ and liberate heat.

ITO particle were synthesized by the modified combustion of aqueous solutions containing stoichiometric amounts of the corresponding metal (Indium and tin) nitrates with fuel $\mathrm{CH}_{2}(\mathrm{NO}) \cdot \mathrm{CH}_{2}$ urea. The precursors have been introduced in such quantities insuring the right stoichiometry is obtained after combustion. We can calculate the numerical coefficients corresponding to a stoichiometric reaction from the total oxidizing and reducing valences of the reactants. Trivalent and divalent metals and the elements $\mathrm{C}, \mathrm{H}, \mathrm{O}$ have respectively valences of $+3,+2,+4,+1$ and -2 . Since during the combustion reaction, a conversion of nitrate in molecular nitrogen takes place, nitrogen is considered to have a valency of zero.

According to this analysis, the total oxidizing valency of $\mathbf{I n}\left(\mathbf{N O}_{3}\right)_{3} \cdot \mathbf{3} \mathbf{H}_{2} \mathbf{O}$ is $(-15)$ and $\mathbf{S n}\left(\mathbf{N O}_{3}\right)_{2} \cdot \mathbf{2} \mathbf{H}_{2} \mathbf{O}$ is $(-8)$ and Urea $(+6)$. The molar number $\psi$ can be calculated using the ratio of combustible/oxidant ratio. In order to obtain one mole of tin nitrate 2 moles of Indium nitrate $\psi$ moles of fuel are then added.

$\psi=$ Total valences of element in the fuel/Total va- 
lences of elements in nitrates

$$
\begin{gathered}
\text { In }(-15)+\operatorname{Sn}(-8)+y(+6)=0 \\
9 \times(-15)+1 \times(-8)+(6) y=0 \\
\Psi=23.83 \mathrm{~g} / \mathrm{mol} .
\end{gathered}
$$

Adiabatic flame temperature $T_{f}$ of the combustion reaction is

$$
T_{f}=298+\frac{\Sigma_{\text {Reactants }}\left(\gamma_{i} x \Delta H_{f, i}\right)-\Sigma_{\text {products }}\left(\gamma_{j} x \Delta H_{f, j)}\right.}{\Sigma_{\text {products }} \gamma_{j} x C_{p}} i n K
$$

$\Delta H_{f}=$ Enthalpy of formation of the products or the reactants respectively.

$C_{p}=$ Heat capacity of the products at constant pressure and at $298 \mathrm{~K}$.

$\gamma=$ Molar number. The flame temperature was calculated as $855 \mathrm{~K}$.

This formula shows that the flame temperature not only depends on the nature of the fuel but also on the fuel to nitrate ratio (depending on the value of $\psi$ ).

When the reaction occurs, it is well known that the measured flame temperature is much lower than the calculated one because of non-adiabatic conditions (heat loss in ambient air).

Use of suitable raw material in combustion synthesis ensures stability of the chemical composition and high quality of products. This work has done with $\left(\mathrm{NH}_{2}\right.$. $\left.\mathrm{CONH}_{2}\right)$ urea as fuel its Combustion heat $(-2.98 \mathrm{kcal} / \mathrm{g})$ [6]. Indium nitrate and tin nitrate are utilized in this study because of its dual role of being the Indium and tin as source and the oxidant. ITO product and gases of $\mathrm{CO}_{2}$, $\mathrm{H}_{2} \mathrm{O}$ and $\mathrm{N}_{2}$ can be formed directly from the reaction between fuel and oxidizer without the necessity of getting oxygen from outside.

\subsection{Physical Characterization of the Powders}

Thermal characteristics of the precursor material were studied on a Netzsch TG/DTA $\left(409^{\circ} \mathrm{C}\right)$ unit at a heating rate of $10^{\circ} \mathrm{C} / \mathrm{min}$. The visible transmission was recorded on a Hitachi S3400NSpectro Photometer. The calcined powders were further characterized by particle size analysis (Autosizer IIC Malvern) and powder X-ray diffraction (XRD) X-ray diffractometer (XRD) with monochromation $\mathrm{CuK}_{\alpha}$ target $\left(1.5406 \mathrm{~A}^{\circ}\right)$ at a scan rate of $2 \%$ min. Unit cell parameter was calculated from the observed "d"-spacing, which was accurately measured with the help of silicon as an internal standard. Varian Cary Eclipse spectrophotometer employing $15 \mathrm{~W}$ Xe flash lamp was used for the photoluminescence studies. The transmittances and band gaps of the ITOs were measuredby using an UV visible spectrometer.

\section{Results and Discussion}

\subsection{TGA and DTA Analysis}

There is an endothermic peak at $105.51^{\circ} \mathrm{C}$ corresponding to the evaporation of $\mathrm{OH}$. There is an endothermic peak at $191.8^{\circ} \mathrm{C}$, too which is shown in Figures 1 and 2. This is due to the existence of organic solvent $\mathrm{CO}, \mathrm{OH}$ desorption. The exothermic peak at $201.38^{\circ} \mathrm{C}$ is heat release by decomposition of organic substance. There is an endothermic peak at $461.47^{\circ} \mathrm{C}$ corresponding to decomposition of indium and tin nitrate and heat absorbing action. The amorphous phases changed into cubic crystal structure cause exothermic peaks at $601.98^{\circ} \mathrm{C}, 687.31^{\circ} \mathrm{C}$. because no impurity is introduced in the experimental process, $\mathrm{SnO}_{2}$ is considered to enter into $\mathrm{In}_{2} \mathrm{O}_{3}$ crystal lattice. The final mass loss percent is $24 \%$ in the TGA graph. Indium tin oxide nanosized composite powder is obtained by sintering ITO powders at $350^{\circ} \mathrm{C}$ for $20 \mathrm{~min}$ [7]. Butin $80 / 20$ there is an endothermic peak at $78.8^{\circ} \mathrm{C}$ corresponding to the evaporation of $\mathrm{OH}$. There is an endothermic peak at $242.24^{\circ} \mathrm{C}$, too which is shown in figure (A and B). This is due to the existence of organic solvent $\mathrm{CO}, \mathrm{OH}$ desorption. The exothermic peak at $281.39^{\circ} \mathrm{C}$ is heat release by decomposition of organic substance. There is an endothermic peak at $456.47^{\circ} \mathrm{C}$ corresponding to decomposition of indium and tin nitrate and heat absorbing action. The amorphous phases changed into cubic crystal structure cause exothermic peaks at $510.66^{\circ} \mathrm{C}$, $615.6^{\circ} \mathrm{C}$. Because no impurity is introduced in the experimental process, $\mathrm{SnO}_{2}$ is considered to enter into $\mathrm{In}_{2} \mathrm{O}_{3}$ crystal lattice. The final mass loss percent is $29 \%$ in the TGA graph. Indium tin oxide nanosized composite powder is obtained by sintering ITO powders at $370^{\circ} \mathrm{C}$ for $20 \mathrm{~min}$.

\subsection{X-Ray Diffraction Studies}

XRD measurements revealed that the ITO film showed a cubic bixbyte structure of indium oxide. The angles at which the peak intensities occur Figures $\mathbf{3}$ and $\mathbf{4}$ are related to the inter-planar distances of the atomic structure of $\mathrm{In}_{2} \mathrm{O}_{3}$ according to Bragg's law: $\mathrm{n} \lambda=2 \mathrm{~d} \sin \theta$. Where $\mathrm{k}$ is the wavelength of X-ray radiation used, $\theta$ is the peak position angle and $\mathrm{d}$ is the inter-planar distance. Therefore the ITO films retain the bulk structure of $\operatorname{In}_{2} \mathrm{O}_{3}(a=$ $\left.10.12 \mathrm{~A}^{\circ}\right)$ but exhibit a slight increase in the lattice constant $\left(a=10.22 \mathrm{~A}^{\circ}\right)$ which was found to be in agreement with the literature [8]. The lattice constant depends on the deposition of parameters and varies for ITO from 10.118 to $10.31 \mathrm{~A}^{\circ}$. These two different proportions have exhibit a strong (222) orientation, revealed by the X-ray studies in the present work.

This indicated complete formation of the cubic phase in both samples at the furnace temperature $\left(500^{\circ} \mathrm{C}\right)$, and 


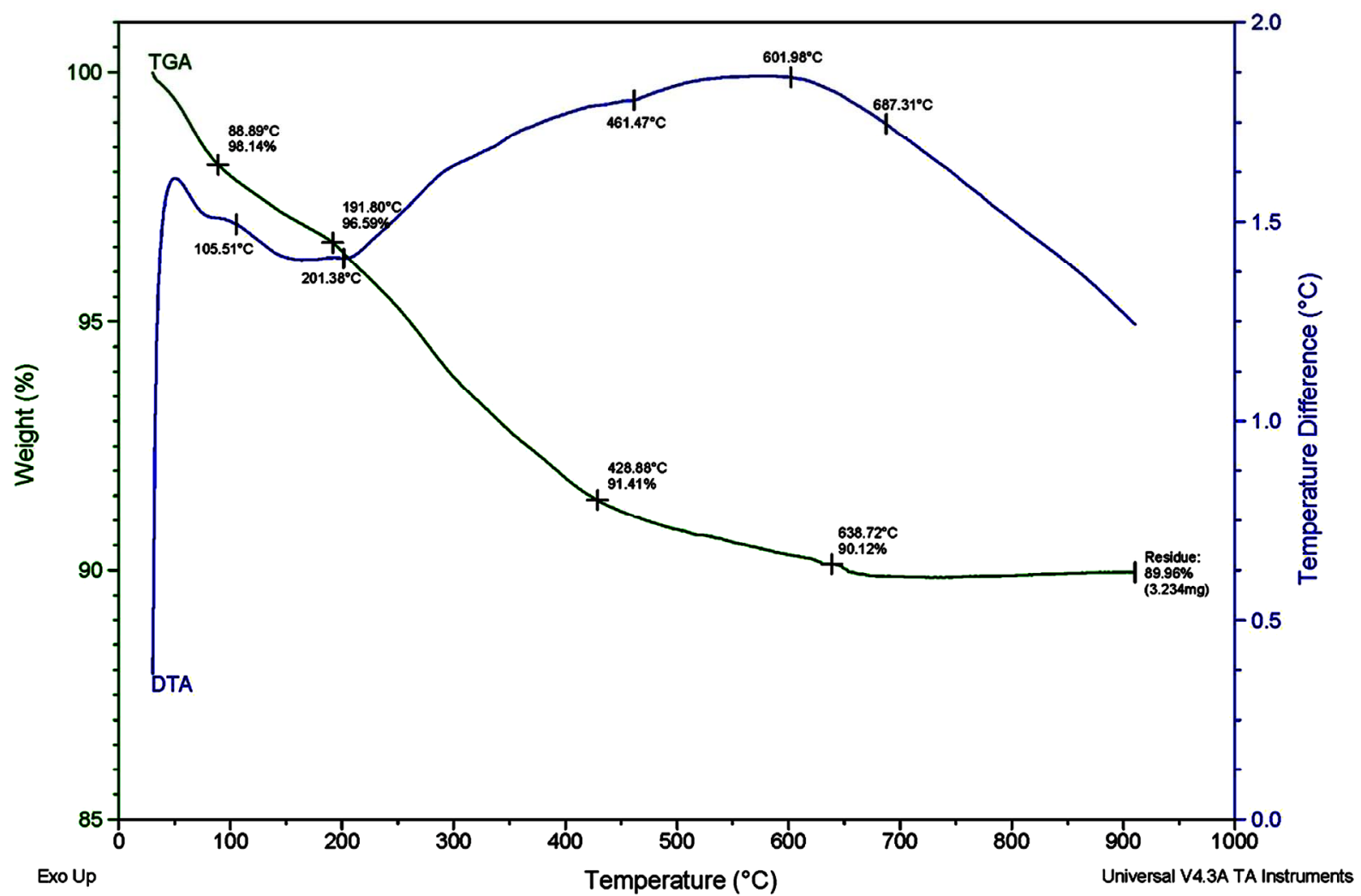

Figure 1. DSC and TGA analysis of $\mathrm{In}_{2} \mathrm{O}_{3} 90 \% \mathrm{SnO}_{2} 10 \%$.

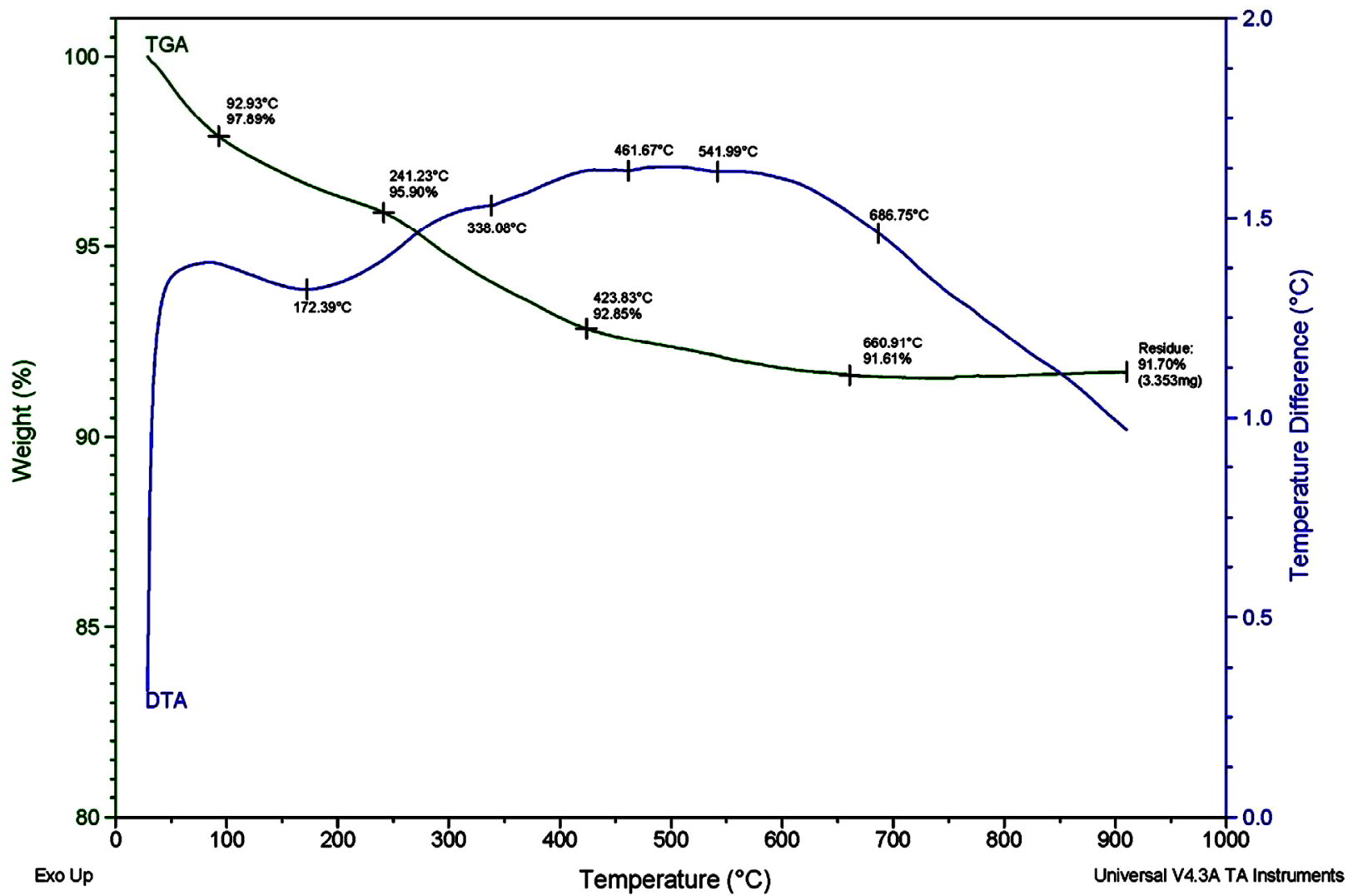

Figure 2. DSC and TGA analysis of $\operatorname{In}_{2} \mathrm{O}_{3} 80 \% \mathrm{SnO}_{2} 20 \%$. 


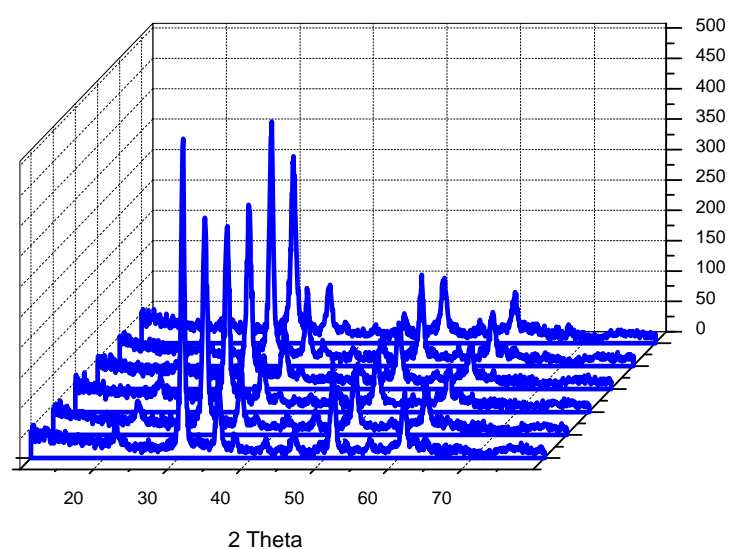

Figure 3. XRD analysis of $\mathrm{In}_{2} \mathrm{O}_{3} 90 \% \mathrm{SnO}_{2} 10 \%$.

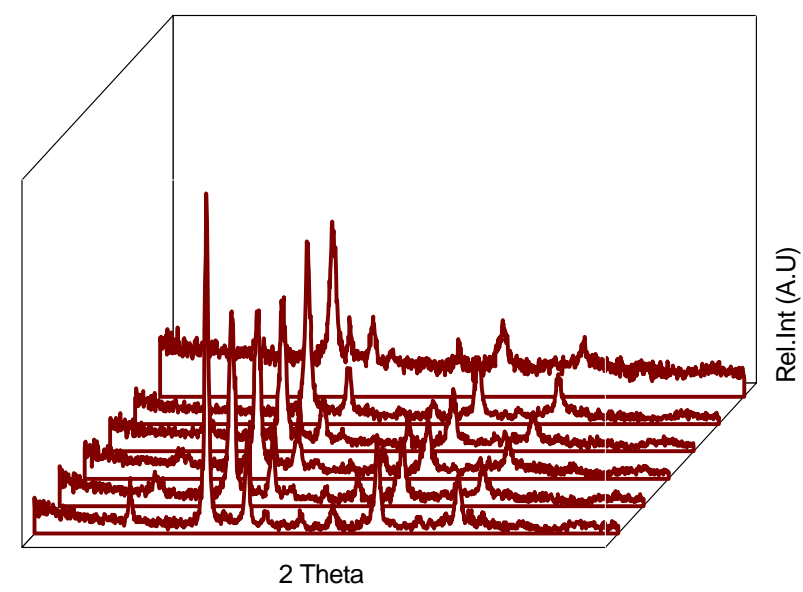

Figure 4. XRD analysis of $\mathrm{In}_{2} \mathrm{O}_{3} 80 \% \mathrm{SnO}_{2} 20 \%$.

no further calcinations treatment was necessary.

The average grain sizes of the powders were calculated with the Scherer Equation (3):

$$
D=\frac{0.9 \lambda}{\beta \cos \theta}
$$

where $\lambda$ is the $\mathrm{X}$-ray wavelength $(0.15406 \mathrm{~nm}), \beta$ is the full width at half-maximum intensity (FWHM) of the diffraction line, and $\theta$ is the Bragg angle. The average grain sizes were $16 \mathrm{~nm}$ and $17 \mathrm{~nm}$ sample 1 and sample 2, respectively.

The lattice parameter was calculated with Equation (4)

$$
a=d_{h k l}\left(h^{2}+k^{2}+l^{2}\right)^{1 / 2}
$$

where, $h k l$ are the Miller indices, for the same crystallattice planes as were used to calculate $D$.

\subsection{Optical Studies}

J. C. Huang et al. [9] reported that a high transparency for the ITO thin films in the visible wavelength region is required in applications such as transparent electrodes in optoelectronic devices. Here an optical transmission spectrum of $10 \mathrm{wt} \%$ and $20 \mathrm{wt} \%$ tin doped ITO nano sized powders are shown in Figures 5 and 6. As can be seen, the optical transmission of ITO powders in the visible wavelength region improved with decreasing doping concentration of $\mathrm{Sn}$. A given material can exhibit a direct or indirect band-to-band transitions which depends on its crystalline structure. The energy gap for direct transition, span the 200 - $1200 \mathrm{~nm}$ range, which were annealed at different temperature. In the whole cases direct transitions were most probable than the indirect transitions. The whole band-gaps of the tin doped $\mathrm{In}_{2} \mathrm{O}_{3}$ powders can be determined by plotting $(\alpha h \gamma)^{\mathrm{n}}$ versus hy, and extrapolating the linear region of the plot toward low energies. Here, $n=2$ is for allowed direct, $n=1 / 2$ for allowed indirect, $n=1 / 3$ for forbidden indirect and $n=2 / 3$ is for forbidden direct optical transitions. This method is approximate for allowed direct electronic band-to-band transitions in semiconductors. For heavily doped semiconductors, this simple method is not valid

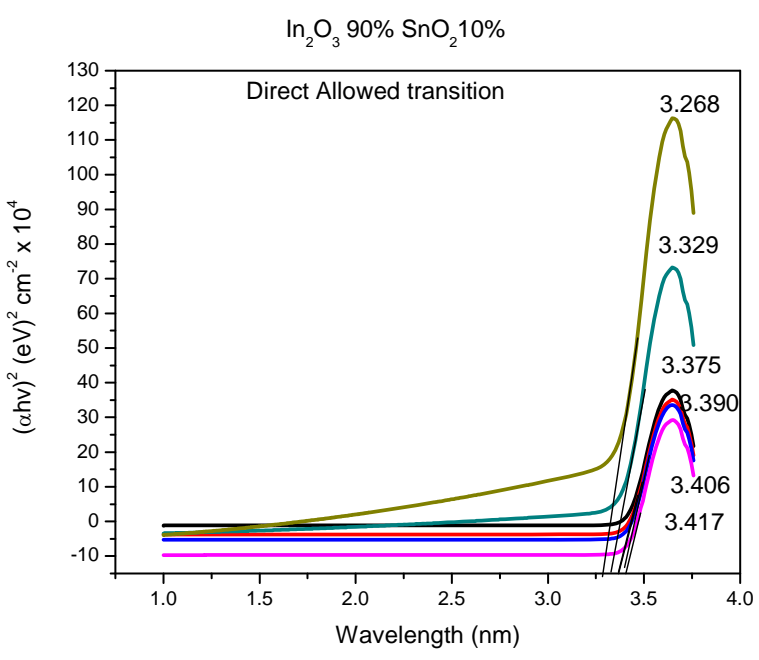

Figure 5. UV-Vis-NIR studies of $\mathrm{In}_{2} \mathrm{O}_{3} 90 \% \mathrm{SnO}_{2} 10 \%$.

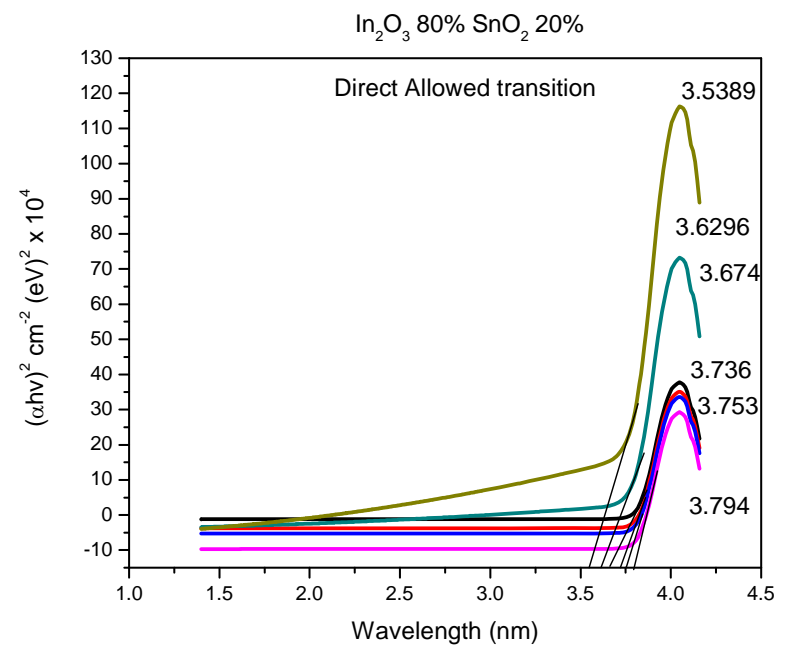

Figure 6. UV-Vis-NIR studies of $\mathrm{In}_{2} \mathrm{O}_{3} 80 \% \mathrm{SnO}_{2} 20 \%$. 
since the lowest states in the conduction band are blocked, and transitions can take place only to energies above the Fermi energy. Thus, the calculated band-gap may be taken only as a rough estimate. Ignoring the reflectivity, which is expected to be low, the absorption coefficient $(\alpha)$ may be determined from the particle transmission [10].

The optical properties of the ITO nanoparticles were analyzed with PL spectroscopy. The PL spectra (excitation at $312 \mathrm{~nm}$ ) of the 10 atom\% Sn doped and 20 atom\% Sn doped nanoparticles with five different temperatures are provided in Figures 7 and 8 . The positions of the emission edges were calculated from the peak positions of the spectra, (90:10, and 80:20). The peaks appeared for (Sample-1) as prepared to different temperatures from $100^{\circ} \mathrm{C}$ to $500^{\circ} \mathrm{C}$ excitation energies are shown in Tables 1 and 2. The observed blue shifts of the peaks confirmed the results of ITO particles which are in nano size. The optical band gap of the nanocrystalline particles depends on the particle radius due to quantum confinement. The

$$
\ln _{2} \mathrm{O}_{3} 90 \% \mathrm{SnO}_{2} 10 \% \text { Asprepared to } 500^{\circ} \mathrm{C}
$$

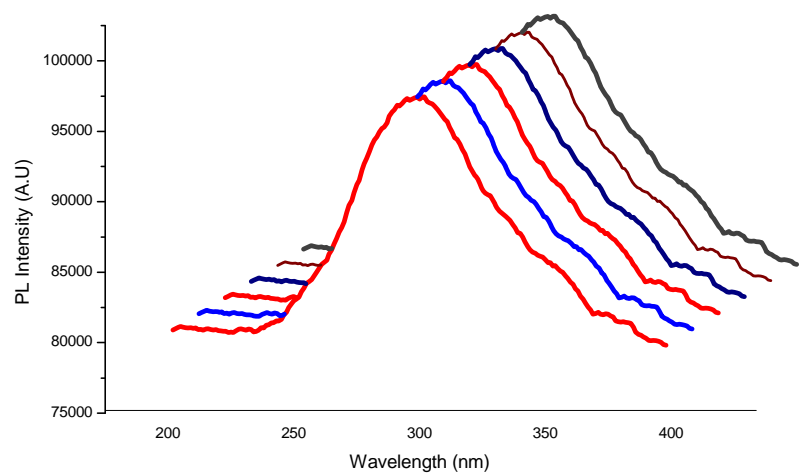

Figure 7. Photoluminescence studies of $\operatorname{In}_{2} \mathrm{O}_{3} \quad 90 \% \mathrm{SnO}_{2}$ $10 \%$.

$$
\ln _{2} \mathrm{O}_{3} 80 \% \mathrm{SnO}_{2} 20 \%
$$

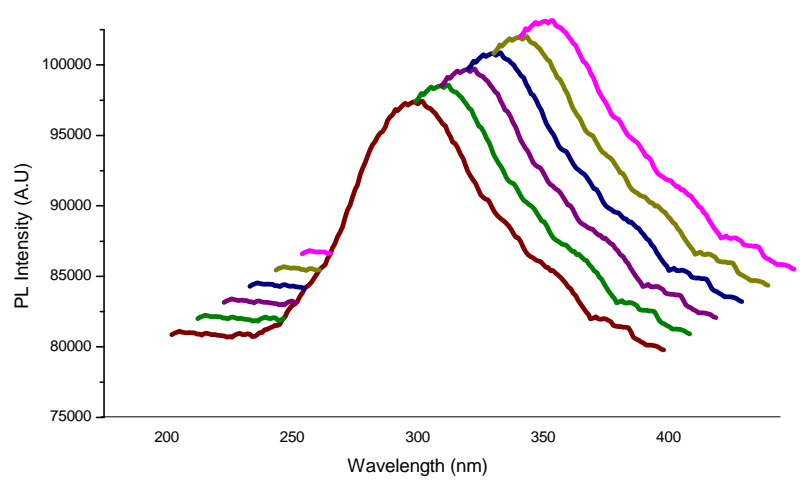

Figure 8. Photoluminescence studies of $\operatorname{In}_{2} \mathrm{O}_{3} \quad 80 \% \mathrm{SnO}_{2}$ $20 \%$.
Table 1. Band gap values of UV-Vis studies.

\begin{tabular}{ccccccc}
\hline Sample & ASP & 100 & 200 & 300 & 400 & 500 \\
\hline $\mathrm{In}_{2} \mathrm{O}_{3} 90 \%$ & 3.268 & 3.329 & 3.375 & 3.390 & 3.408 & 3.417 \\
$\mathrm{SnO}_{2} 10 \%$ & & & & & & \\
$\mathrm{In}_{2} \mathrm{O}_{3} 80 \%$ & 3.5389 & 3.6296 & 3.674 & 3.738 & 3.753 & 3.794 \\
$\mathrm{SnO}_{2} 20 \%$ & & & & & & \\
\hline
\end{tabular}

Table 2. Band gap values of photoluminescence studies.

\begin{tabular}{ccccccc}
\hline Sample & Aspre & $100^{\circ} \mathrm{C}$ & $200^{\circ} \mathrm{C}$ & $300^{\circ} \mathrm{C}$ & $400^{\circ} \mathrm{C}$ & $500^{\circ} \mathrm{C}$ \\
\hline $\mathrm{In}_{2} \mathrm{O}_{3} 90 \%$ & 3.912 & 3.949 & 3.974 & 4.039 & 4.106 & 4.161 \\
$\mathrm{SnO}_{2} 10 \%$ & & & & & & \\
$\mathrm{In}_{2} \mathrm{O}_{3} 80 \%$ & 3.8154 & 3.875 & 3.899 & 3.9365 & 4.066 & 4.119 \\
$\mathrm{SnO}_{2} 20 \%$ & & & & & & \\
\hline
\end{tabular}

approach to quantitative determination of the size dependence of the band gap energy $\left(E_{b}\right)$ is based on the effective mass approximation (EMA). The increase in optical band gap $\left(\Delta E_{b}\right)$ of a nanocrystalline semiconductor may be represented as

$$
\Delta E_{b}=E_{e f f}-E_{b u l k}=\frac{h^{2}}{8 \mu R^{2}}-\frac{1.8 e^{2}}{R \varepsilon}
$$

where $E_{\text {eff }}$ is the band gap of the nanocrystalline material, $E_{\text {bulk }}$ is the band gap of the material in bulk form, $\mu$ is the electron-hole effective mass and $\varepsilon$ is the dielectric constant and is equal to 9 for ITO [11]. The first term in the Equation (5) represents the particle in-box quantum localization energy and had simple $\frac{1}{R^{2}}$ dependence, where $R$ is the particle radius; the second term represents the Coulomb energy with $\frac{1}{R}$ dependence. The radii of the nanocrystals of ITO calculated from Equation (5) match reasonably well with the previously calculated values. The blue shift is observed as the temperature of the particle increases, indicating that the nanoparticles arein the quantum confinement regime [12]. As the $\mathrm{Sn}$ content increases, the PL emission maxima $\left(\mathrm{In}_{2} \mathrm{O}_{3} 80 \%\right.$ $\mathrm{SnO}_{2} 20 \%$ ) become blue shifted. The UV-Vis absorption spectra reveal a similar trend in absorption maxima according to Sn content.

\section{Conclusion}

Structural, optical and electrical properties of two proportions $(10$ atom $\%, 20$ atom $\%$ ) tin doped indium oxide powders with $<25 \mathrm{~nm}$ and $<25 \mathrm{~nm}$ in grain size which annealed in a furnace of $1 \mathrm{hr}$ at five different temperatures range from $100^{\circ} \mathrm{C}$ to $500^{\circ} \mathrm{C}$ in air atmosphere were studied. The XRD results showed that the crystallinity of ITO powder was improved with annealing $<25 \mathrm{~nm}$ in grain size obtained at different temperature which slowly increases with respect to temperature insteps of $100^{\circ} \mathrm{C}$. The 
allowed direct band gap energies were calculated and were in good agreement with published values of ITO powders and thin films. The absorption length calculation indicates that indirect band to band transitions mostly take place. The results also show that by increasing annealing temperature, the conductance of ITO powders was increased. Further, from the results we may conclude that the annealing temperature plays a major role in controlling the optical transmittance of the nanoparticle.

\section{REFERENCES}

[1] F. O. Adurodija, L. Semple and R. Bruning, "Crystallization Process and Electro-Optical Properties of $\operatorname{~n}_{2} \mathrm{O}_{3}$ and ITO Thin Films," Journal of Materials Science, Vol. 41, No. 21, 2006, pp. 7096-7102. doi:10.1007/s10853-006-0038-3

[2] S. Deki, S. Iizuka, M. Mizuhata and A. Kajinami, "Fabrication of Nano-Structured Materials from Aqueous Solution by Liquid Phase Deposition," Journal of Electroanalytical Chemistry, Vol. 584, No. 1, 2005, pp. 38-43. doi:10.1016/j.jelechem.2004.05.027

[3] A. Nakata, M. Mizuhata and S. Deki, "Novel fabrication of Highly Crystallized Nanoparticles in the Confined System by the Liquid Phase Deposition (LPD) Method," Electrochimica Acta, Vol. 53, No. 1, 2007, pp. 179-185. doi:10.1016/j.electacta.2007.06.025

[4] A. Soliman and M. A. Aegerter, "Modeling of optical and Electrical Properties of $\operatorname{In}_{2} \mathrm{O}_{3}:$ Sn Coatings Made by Various Techniques," Thin Solid Films, Vol. 502, No. 1-2, 2006, pp. 205-211. doi:10.1016/j.tsf.2005.07.277
[5] H.-L. Lü, et al., "Nanocrystals of $\mathrm{Co}^{2+}$-Doped $\mathrm{MgGa}_{2} \mathrm{O}_{4}$ : Preparation by a Low-Temperature Combustion Method and Optical Properties," Journal of the Chinese Chemical Society, Vol. 56, 2009, pp. 323-326.

[6] C.-C. Hwang and T.-Y. Wu, "Synthesis and Characterization of Nanocrystalline ZnO Powders by a Novel Combustion Synthesis Method," Materials Science and Engineering B, Vol. 111, No. 2-3, 2004, pp. 197-206.

[7] J. X. Liu, et al., "Indium Tin Oxide Nano Sized Composite Powder Prepared Using Waste ITO Target," Rare Metals, Vol. 24, No. 3, 2005.

[8] A. Gupta, et al., "Thin Fluorine-Doped Tin Oxide Films Prepared Using an Electric Field-Modified Spray Pyrolysis Deposition Technique," Japanese Journal of Applied Physics, Vol. 43, 2004, pp. L1592-L1594. doi:10.1143/JJAP.43.L1592

[9] J. C. Huang and G. T. Gray, "Substructure Evolution and Deformation Modes in Shock-Loaded Niobium," Materials Science and Engineering: A, Vol. A103, No. 2, 1988, pp. 241-255.

[10] A. N. Tiwari, et al., "Electrical and optical properties of single phse CuInS2 Films prepared by Spray Pyrolysis," Thin Solid Films, Vol. 130, No. 3-4, 1985, pp. 217-230. doi:10.1016/0040-6090(85)90353-0

[11] S. Das, et al., "Optical Properties of $\mathrm{SnO}_{2}$ Nanoparticles and Nanorods Synthesized by Solvothermal Process," Journal of Applied Physics, Vol. 99, 2006, pp. 114303114310. doi:10.1063/1.2200449

[12] J. J. Urban, D. V. Talapin, E. V. Shevchenko and C. B. Murray, "Self-Assembly of PbTe Quantum Dots into Nanocrystalsuperlattices and Glassy Films," Journal of the American Chemical Society, Vol. 128, No. 10, 2006, pp. 3248-3255. doi: $10.1021 / \mathrm{ja} 058269 \mathrm{~b}$ 